\title{
Subcutaneous Emphysema Associated with Pneumomediastinum and Complicated Pneumopericardium in a 14-Month-Old Infant
}

\author{
K. Sacko1,2, B. Maiga1,2, G. Dembelé2, P. Togo², Y. Coulibaly1, A. Dembélé2, F. Traoré1,2, \\ H. Ba ${ }^{2}$, A. Touré2, K. Traoré ${ }^{2}$, N. L. Sidibé1,2, F. L. Diakité1,2, A. Sangaré2, O. Coulibaly², \\ H. Konaré2, I. Ahamadou'2, Y. A. Coulibaly ${ }^{2}$, M. E. Cissé2, S. Sagara ${ }^{2}$, D. Konaté1,2, \\ A. K. Doumbia' ${ }^{2}$, M. Kanta ${ }^{3}$, H. Diall2 ${ }^{2}$ L. Maiga ${ }^{2}$, R. Fané ${ }^{2}$, A. Cissouma ${ }^{2}$, N. L. Traoré2, \\ M. Niakaté ${ }^{2}$ A. A. Diakité1,2
}

${ }^{1}$ Faculty of Medicine and Odontosmatology, University of Sciences, Techniques and Technology of Bamako, Bamako, Mali ${ }^{2}$ Department of Pediatrics of the University Hospital Gabriel Toure, Bamako, Mali

${ }^{3}$ Sickle Cell Disease Control and Research Center, Bamako, Mali

Email: Karamoko_sacko@yahoo.fr, sackokaramoko@gmail.com

How to cite this paper: Sacko, K., Maiga, B., Dembelé, G., Togo, P., Coulibaly, Y., Dembélé, A., Traoré, F., Ba, H., Touré, A., Traoré, K., Sidibé, N.L., Diakité, F.L., Sangaré, A., Coulibaly, O., Konaré, H., Ahamadou, I., Coulibaly, Y.A., Cissé, M.E., Sagara, S., Konaté, D., Doumbia, A.K., Kanta, M., Diall, H., Maiga, L., Fané, R., Cissouma, A., Traoré, N.L., Niakaté, M. and Diakité, A.A. (2021) Subcutaneous Emphysema Associated with Pneumomediastinum and Complicated Pneumopericardium in a 14 -Month-Old Infant. Open Journal of Pediatrics, 11, 108113.

https://doi.org/10.4236/ojped.2021.111010

Received: December 14, 2020

Accepted: March 7, 2021

Published: March 10, 2021

Copyright ( 2021 by author(s) and Scientific Research Publishing Inc. This work is licensed under the Creative Commons Attribution International License (CC BY 4.0).

http://creativecommons.org/licenses/by/4.0/

\begin{abstract}
Pneumomediastinum is sometimes observed in adult patients but its occurrence in pediatric patients (especially infants) is very rare. We here report a 14-month-old male infant who had subcutaneous emphysema, pneumomediastinum, and importantly, pneumopericardium. He had no particular past histories. He abruptly had cough, fever, and eruption on the abdomen. Computed tomography and echocardiography revealed pneumomediastinum and pneumopericardium. Antibiotics, rest, and supportive therapy ameliorated the condition. We must be aware that pneumomediastinum, and importantly pneumopericardium, can be present in a pediatric patient with subcutaneous emphysema. The infant's symptoms disappeared under strict monitoring of respiratory status, nasal oxygen therapy and antibiotic therapy.
\end{abstract}

\section{Keywords}

Subcutaneous Emphysema, Pneumopericardium, Infant, Bamako, University Hospital Gabriel Touré

\section{Introduction}

Subcutaneous emphysema is the presence of air under the skin, giving an anusual crackling sensation (crepitus) by palpation like walking on snow, most often located in the inferior region of the neck and thorax following a pneumomedias- 
tinum and/or pneumothorax, but its association with a pneumopericardium is rarely described [1] [2]. The initial mechanism is a breach in the tracheobronchial tree with diffusion of air into the interstitial space and along the perivascular spaces to the mediastinum, followed by propagation and diffusion in the subcutaneous tissues [3]. The etiologies are dominated by traumatic causes, inhalation of foreign bodies, asthma attacks and infections [1] [3]. We are reporting the observation of a 14-months old-infant with subcutaneous emphysema, a spontaneous pneumomediastinum and complicated by a pneumopericardium. Patient data have been treated with respect of all ethical aspects, particularly anonym.

\section{Observation}

The case involved a 14-month-old male infant referred by a second-level health facility for suspicion of subcutaneous emphysema. He had no particular antecedent with a good psychomotor and stature-ponderal development. We noted a fracture of the left humerus which was 3 months old, treated traditionally. His vaccination according to the country's programme was up to date. The onset of symptoms was 10 days ago, marked by a cough, a fever and the appearance of pustular lesions on the abdomen. The diagnosis of acute lower respiratory infection was made at the health center and the infant received oral antibiotics (Erythromycin) and oral anti-inflammatory drugs (Ibuprofen). A few days later, due the appearance of a thoracic and right periorbital tumour, the second level health facility sent him to us for treatment. During the interrogation, we did not find any notion of asthma, repetitive pneumopathies, swallowing disorder, recent traumatism, dental extration or recent surgical gesture. In the physical examination we find a weight of $10 \mathrm{~kg}$, a height of $82 \mathrm{~cm}$, a head circumference of $46 \mathrm{~cm}$ and an axillar temperature of $36.9^{\circ} \mathrm{C}$. The infant was in good general condition with a good mucocutaneous colouring, there were pustular and oozing lesions on the abdominal area. There was also the presence of a painless tumour in the upper part of the thorax extending over the back, neck and face, the palpation of which gave snowy crepitations (subcutaneous emphysema), a spongy swelling of the eyelids accentuated on the right (Figure 1). The pulmonary examination found a discret sign of respiratory distress, an oxygen saturation of $92 \%$ and a respiratory frequency of $42 \mathrm{cycles} / \mathrm{min}$. The lung auscultation was normal. Heart sounds were audible without breath with tachycardia at 176 beats/min. No heart murmur was perceived. The neurological and digestive examination were unremarkable. The postero-anterio chest X-ray (Figure 2) showed subcutaneous emphysema, pneumomediastinum and cardiomegaly. An echocardiography found a pneumopericardium (Figure 3).

Thoracic CT scan objectively showed subcutaneous emphysema, mediastinal effusion and confirmed pneumopericardia (Figure 4). A neutrophilic hyperleukocytosis $\left(14,000 / \mathrm{mm}^{3}\right)$ was found in the blood count and the protein-C reative was $47 \mathrm{mg} / 1$. The treatment of our infant was based on strict monitoring of the respiratory condition, nasal oxygen therapy at $1 \mathrm{~L} / \mathrm{min}$ and antibiotics based on 
Certriaxone at $100 \mathrm{mg} / \mathrm{kg}$ per day for ten days combined with Gentamycin at 3 $\mathrm{mg} /$ day for three days. The evolution was marked by clinical and radiological improvement with the regression of subcutaneous emphysema and cough on the sixth day of hospitalization (Figure 5). The infant was discharged on the tenth day after all clinical and radiological signs had disappeared.

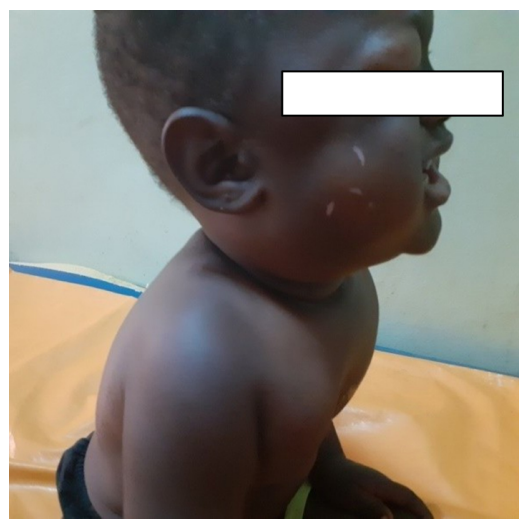

Figure 1. Photo of the infant on admission.

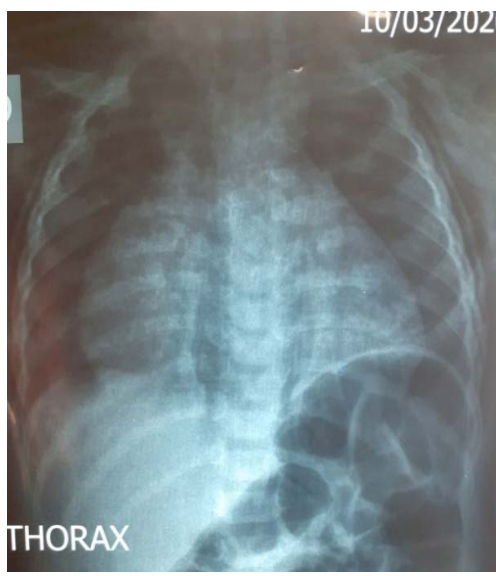

Figure 2. Frontal chest x-ray: shows cardiomegaly (red arrow) and pneumothorax (blue arrow).

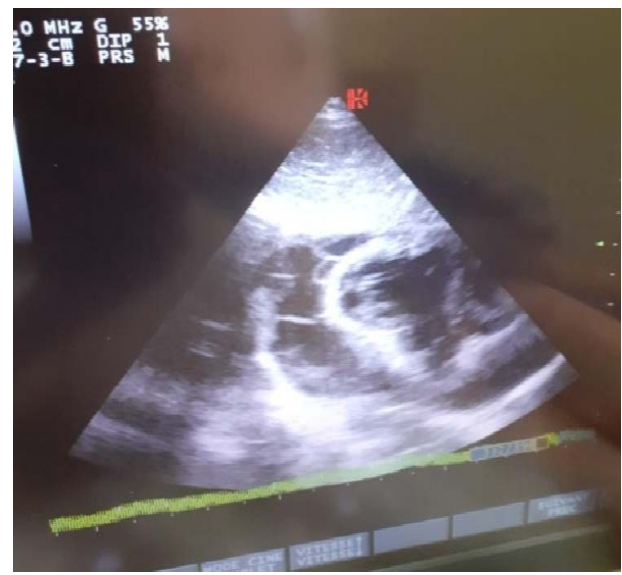

Figure 3. Ultrasound image showing pneumopericardium (blue arrow). 


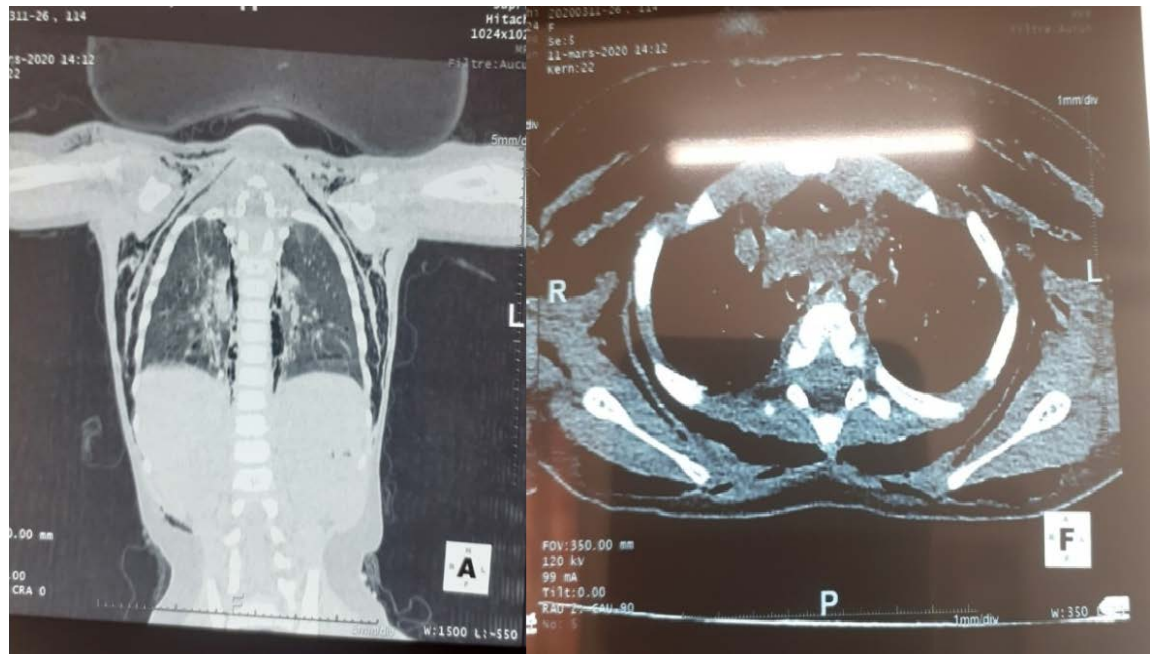

Figure 4. Chest CT images.

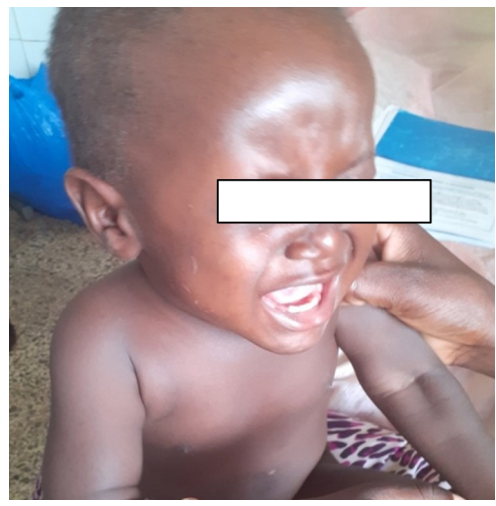

Figure 5. Infant is discharged.

\section{Discussion}

Described since 1939 in the adult population, spontaneous pneumomediastinum (SPM) is less well known in children. We are reporting the case of a 14-monthold male infant, without any past history, the particularity of our observation resides in the young age of the patient (14 months) and the association of a pneumopericardium with pneumomediastinum. In 2008, Oudin C et al. reported the case of a 4-month-old infant with acute bronchiolitis complicated by spontaneous pneumomediastinum without favourable progression of pneumopericardium under medical treatment [4]. Our patient presented with a soft swelling in the upper chest area and extended to the back, neck and face with crackling sensation on palpation. Crackling sensation on palpation like walking on snow are key semiological elements in the diagnosis of subcutaneous emphysema. A spongy appearance of the skin can be noted in case of massive emphysema as in our observation of the eyelids. In our patient, the pulmonary inspection showed a respiratory depression without auscultatory abnormality, which is in line with the literature where dyspnea was found in about $2 / 3$ of the cases [4] [5]. In addition to the subcutaneous emphysema, our patient had a pneumomediastinum dis- 
covered on the chest X-ray (Figure 3), which is pathophysiologically due to an increase in intra-alveolar pressure, which leads to the formation of breaches in the alveolar wall [6]. In 2007, Bullaro F, in his study on spontaneous pneumomediastinum in children, found that SPM is most often observed in asthmatics, but can also occur in any patient after Valsalva manœuvre, including coughing, violent vomiting or a first wheezing, our patient had a cough that could be the triggering cause [7]. Our patient presented with a pneumopericardium objectivelly confirmed by cardiac echography and thorax CT scan which concluded to a pericardial effusion of great abundance with no tamponade signs (Figure 5). Pneumopericardia may be an occasional complication of pneumomediastinum. The treatment of our infant was based on strict monitoring of the respiratory condition combined with nasal oxygen therapy at $1 \mathrm{~L} / \mathrm{min}$ and antibiotic therapy with Certriaxone at $100 \mathrm{mg} / \mathrm{kg}$. The same therapeutic approach had been found in several authors in the literature [1] [7]. The evolution of our patient was marked by a fully clinical and radiological recovery with the regression of subcutaneous emphysema and cough on the sixth day of hospitalisation. In the vast majority of cases the evolution was favourable, as in the study by Oudin et al. [4].

\section{Conclusion}

Subcutaneous emphysema associated with spontaneous pneumomediastinum is a rare pathology, its association with a pneumopericardium in a 14-month-old infant is the particularity of this observation. The treatment was based on strict surveillance, supportive and antibiotic therapy. The evolution was favourable with the disappearance of the signs in 10 days of hospilization. It would be important in any case of subcutaneous emphysema to perform a thoracic CT scan or, at least a cardiac ultrasound in search of a pneumopericardium.

\section{Conflicts of Interest}

The authors declare no conflicts of interest regarding the publication of this paper.

\section{References}

[1] Rkain, M., Seddiki, A., Ouali, A., Amrani, R. and Benajiba, N. (2016) Spontaneous Subcutaneous Emphysema Associated with Pneumomediastinum and Pneumopericardium: About a New Observation. Medical journal Readaptation, 30, 1-4.

[2] Mathieu, E. (2009) Subcutaneous Thoracic Emphysema. Dusymptome à la prescription en médecine générale. Elsevier Masson, Paris, 431-435. https://doi.org/10.1016/B978-2-294-01781-0.50082-0

[3] Maunder, R.J., Pierson, D.J. and Hudson, L.D. (1984) Subcutaneous and Mediastinal Emphysema. Physiopathology, Diagnosis and Management. Intern Med Arch, 144, 1447-1453.

[4] Oudin, C., Halbert, C., Bosdure, E., Arlaud, K., Chabrol, B. and Dubus, J.-C. (2008) Spontaneous Pneumomediastinum in a 14-Month-Old Infant. Archives de Pédiatrie, 15, 1652-1655. https://doi.org/10.1016/j.arcped.2008.07.021 
[5] Le Loch, J.B., Freymond, N., Khettab, F., Pacheco, Y. and De Vouassoux, G. (2008) Pneumomediastinum, Giant Subcutaneous Emphysema and Pneumoperitoneum of Dental Origin Unusual Pathology of a Pneumomediastinum. Clinical Pneumology Review, 64, 30-33. https://doi.org/10.1016/j.pneumo.2008.06.002

[6] Hmamia, F., Oulmaatia, A., Bouboub, M., Chakib, B.M., Hidad, M. and Bouharrou, A. (2015) Massive Subcutaneous Emphysema, Pneumomediastinum, Pneumopericardium, Pneumorachis and Pneumoretro Revaling Unknown Inhalation of a Foreign Body. Archives de Pédiatrie, 22, 978-981.

[7] Bullaro, F.M. and Bartoletti, S.C. (2007) Spontaneous Pneumomediastinum in Infants: Review of the Literature. Paediatric Emergency Care, 23, 28-30.

https://doi.org/10.1097/01.pec.0000248686.88809.fd 